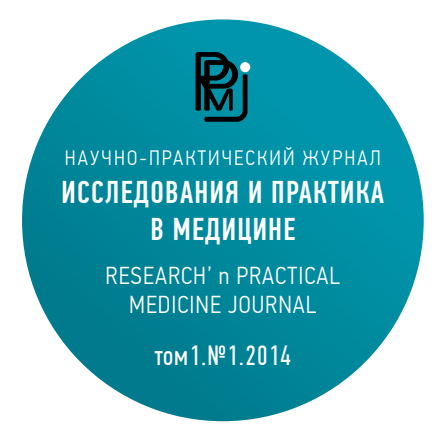

Ключевые слова:

импортозамещение, просидол, терапия хронического болевого синдрома у окологических больHыX

Keywords:

import substitution, prosidol, chronic pain syndrome in cancer patients

\section{СОВРЕМЕННЫЕ ВОЗМОЖНОСТИ ИМПОРТОЗАМЕЩЕНИЯ В ЛЕЧЕНИИ БОЛЕВЫХ СИНДРОМОВ У ОНКОЛОГИЧЕСКИХ БОЛЬНЫХ}

\author{
Абузарова Г.Р. ${ }^{1}$, Алексеева Г.С. ${ }^{2}$, Сарманаева Р.P' ${ }^{1}$, Душакова Л.В. ${ }^{2}$
}

1 МНИОИ им. П.А.Герцена — филиал ФГБУ «ФМИЦ им. П.А.Герцена» Минздрава России (Москва, Российская Федерация)

125284, Российская Федерация, Москва, 2-ой Боткинский проезд, дом 3

2 ФГБУ «ФМИЦ им. П.А.Герцена» Минздрава России (Обнинск, Российская Федерация)

249036, Российская Федерация, Калужская область, г. Обнинск, ул. Королёва, д. 4

\section{Резюме:}

Цель. Оценить эффективность и безопасность просидола в защечных таблетках в терапии хронического болевого синдрома у онкологических больных. Материалы и методы исследования. Исследование проводилось у 152 онкологических пациентов с хроническими болевыми синдромами, вызванными злокачественными новообразованиями. Объективизация интенсивности боли проводилась по 5-балльной шкале вербальных оценок (ШВО), оценивали состояние физической активности больных по 5-бальной шкале ECOG, объективизировали психический статус и ночной сон: 0-боли нет; 1 - слабая боль; 2 - умеренная боль; 3 - сильная боль; 4 балла нестерпимая боль. Регистрировали продолжительность анальгетического эффекта просидола, рассчитывали разовые и суточные дозы анальгетика в динамике на этапах терапии и его побочные эффекты. Результаты исследования оценивались на этапах: 1 - исходный, до начала лечения, 2 - первые сутки терапии, 3-завершение подбора дозы анальгетика (3-4 сутки), 4 через неделю после начала лечения, 5 - через 2 недели после начала лечения, 6 - в конце 3-й недели лечения.

Результаты. Начальная разовая доза просидола буккального (20 мг) вызывала эффективную анальгезию через $10-45(21,3+8,9)$ мин. после приема первой дозы и продолжалось от 1 до $8(6,0+1,8)$ часов: у 21,8\% пациентов - полное устранение боли (более, чем на $50 \%$ от исходного уровня); у $63,6 \%$ - боль уменьшилась на 30-50\%; уменьшение боли менее $30 \%-$ у $14,6 \%$ больных. В целом выявлено достоверное снижение интенсивности боли с 2,47+0,37 до 0,5+0,30 балла ВАШ $(p<0,05)$. Случаев неэффективности препарата не отмечено. Все пациенты продолжали терапию просидолом после завершения 3-х недельного периода исследования. Начальная средняя суточная доза просидола составила 82,2 + 9,7 мг, на 1-й неделе терапии - 112,3+16 мг, к концу 3-й недели повысилась до 148,2+57 мг/сут мг. Переносимость препарата расценивалась, как хорошая. Побочные эффекты: сонливость и тошнота у большинства отмечались на 1-3 сут. терапии были выражены умеренно или слабо у 85\% больных (сонливость - 62,3\%, тошнота - 27,3\%, рвота - 15\%; сухость во рту - 65,5\%, головокружение $-27,6 \%$ ). Ночной сон стабилизировался у $85 \%$ (относительно $13 \%-$ на исходном этапе); число больных с явлениями депрессии уменьшилось в 1,8-2,2 раза.

Заключение. Просидол буккальный в суточной дозе от 60 до 200 мг в обеспечивает эффективную анальгезию у большинства онкологических больных с хроническим болевым синдромом от умеренного до сильного при умеренно выраженных побочных эффектах, которые не опасны, хорошо поддаются медикаментозной коррекции. Просидол в сублингвальных таблетках обладает основными свойствами, предъявляемыми современной медициной к опиоидным для терапии хронической раковой боли: он эффективен, безопасен, лучше, чем другие наркотики переносится пациентами, удобен для самостоятельного применения тяжелобольными в амбулаторных и домашних условиях. Недостатком просидола буккального является кратковременность эффекта (в среднем 4 ч) 


\title{
MODERN POSSIBILITIES OF IMPORT SUBSTITUTION IN THE TREATMENT OF PAIN SYNDROME IN CANCER PATIENTS
}

\author{
Abuzarova G.R. ${ }^{1}$, Alekseeva G.S. ${ }^{2}$, Sarmanaeva R.R. ${ }^{1}$, Dushakova L.V. ${ }^{2}$ \\ ${ }^{1}$ Moscow Oncology Institute of the Hertsen FMRC MH RF (Moscow, Russian Federation) 3, 2 Botkinskiy proezd, 125284, Russian Federation, Moscow \\ ${ }^{2}$ Hertsen FMRC MH RF (Obninsk, Russian Federation) 4, st. Korolev, 249036, Russian Federation, Kaluga region, Obninsk
}

\begin{abstract}
:
Objective. To evaluate the efficacy and safety of prosidol in cheek tablets in the treatment of chronic pain syndrome in cancer patients.

Material and methods. The study was conducted at 152 cancer patients with chronic pain syndrome caused by malignant neoplasms. The objectification of pain intensity was conducted on a 5 - point verbal scale assessments (SVA), assessed the state of physical activity of patients on a 5-point scale ECOG, objectified the mental status and a night's sleep: 0-no pain; 1 - slight pain; 2 - moderate pain; 3 - severe pain; 4 points unbearable pain. We registered the duration of analgesic effect of prosidol, calculated single and daily doses of analgesic in the dynamics on the stages of therapy and its side effects. The results of the study were assessed on stages: 1 - initial, before treatment, 2 - first day of therapy, 3 - completion of the selection of doses of analgesic (3-4 days), $4-a$ week after the start of treatment, 5-2 weeks after the start of treatment, $6-$ at the end of the 3rd week of treatment.

Results. Initial single dose of buccal prosidol $(20 \mathrm{mg})$ caused effective analgesia after 10 to $45(21,3+8,9)$ minutes after the first dose and lasted from 1 to $8(6,0+1,8)$ hours: $21.8 \%$ of patients complete elimination of pain (more than $50 \%$ from baseline); in $63.6 \%$ of the pain was reduced by $30-50 \%$; reduction of pain less than $30 \%-$
\end{abstract}

in $14.6 \%$ of patients. In General, a significant decrease in the intensity of pain with $2,47+0.37$ to 0.5 to +0.30 VAS score $(p<0.05)$. The failures of the drug were observed. All patients continued prosidol therapy after a 3-week study period. The initial average daily dose of prosidol was $82.2+9,7 \mathrm{mg} ; 1$ week of therapy $-112,3+16 \mathrm{mg}$, by the end of the $3 \mathrm{rd}$ week increased to $148,2+57 \mathrm{mg} /$ day $\mathrm{mg}$ Tolerability was judged as good. Side effects: drowsiness and nausea most noted for 1-3 days of therapy was expressed moderately or weakly in $85 \%$ of patients (drowsiness of $62.3 \%$, nausea is $27.3 \%$, vomiting in $15 \%$; dry mouth is $65.5 \%$, dizziness) to $27.6 \%$ ). Night sleep was stabilized at $85 \%$ (relative to $13 \%$ in the initial stage); the number of patients with symptoms of depression decreased in 1.8-2.2 times.

Conclusion. Buccal Procidol in a daily dose of from 60 to $200 \mathrm{mg}$ provides effective analgesia in the majority of cancer patients with moderate to strong chronic pain at moderately pronounced side effects which are not dangerous, respond well to medical treatment. Procida in sublingual tablets possesses the basic properties required of modern medicine to opioid therapy for chronic cancer pain: it is effective, safe, better tolerated than other drugs, convenient for the independent application of patients in outpatient and home. The lack of buccal prosidol is the short duration of effects (average 4 hours).
В 1986 г Всемирная организация здравоохранения (ВО3) наряду с задачей раннего выявления злокачественных новообразований (зНО) впервые провозгласила необходимость оказания паллиативной помощи и полноценного обезболивания пациентам генерализованными опухолевыми процессами.

Почти 30 лет тому назад, в 1986 г ВОЗ выпустила первое руководство, содержащее методику снятия болевых синдромов у онкологических больных «Обезболивание при раке», в которой были изложены принципы обезболивания при онкологических заболеваниях, включая применение трехступенчатой «лестницы обезболивания». Эта методика разрабатывалась коллективом специалистов Секции онкологии ВОЗ и была направлена на разработку национальных программ борьбы с 3 НО в мировом масштабе, поскольку многие пациенты с генерализованными формами опухолей нуждаются в паллиативном лечении, а обезболивающая терапия является важнейшим его звеном. Опиоидные анальгетики в неинвазивных формах были провозглашены основным средством терапии боли у большинства онкологических больных с рас- пространенными формами ЗНО. Основным препаратом тогда был признан морфин в лекарственных формах для приема через рот (таблетки, раствор, сироп).

Руководство ВОЗ неоднократно дополнялось и переиздавалось, но основные его постулаты оставались незыблемы: «через рот» (неинвазивно), «по часам», «по восходящей», «индивидуально» и «с вниманием к деталям».

С точки зрения ВОЗ в каждой стране должен иметься в наличии сильнодействующий опиоидный анальгетик, который был бы легко доступен для пациентов и широко применялся во всех условиях от стационаров до ухода на дому. Кроме базовых препаратов, предложенных ВОЗ для обезболивания (морфин, бупренорфин, фентанил, оксикодон, гидроморфон и метадон) предлагалось применять опиоидные анальгетики с учетом региональных или национальных особенностей, то есть те препараты, которые производятся или имеются в наличии в соответствующих странах.

С этой точки зрения в России имеется свой опиоидный анальгетик, который производится из отечественного сы- 
рья, поскольку полностью синтезируется у нас в стране просидол (пропионилфенилэтоксиэтилпиперидин). Хотя анальгетический эффект этого препарата несколько ниже, чем у «золотого стандарта» - морфина, однако это не может принизить его уникальных свойств, как лучшего препарата для инициации опиодной терапии, препарата для поддержания анальгезии при хронической боли и лечении прорывов боли на фоне приема других более сильных опиоидных анальгетиков (ТTС фентанила и морфина сульфата в таблетках продленного действия-МСТ). Следует учесть, что просидол, в сравнении с морфином, характеризуется лучшей переносимостью, меньшим числом и выраженностью побочных эффектов.

Терапия наркотиками не представляет больших проблем, если пациент находится в стационаре под наблюдением врачей-специалистов, которые назначают пациенту необходимый препарат и контролирует процесс лечения боли. При амбулаторной терапии, особенно у находящегося дома пациента, на первый план выходят эффективность и безопасность обезболивания наркотическим анальгетиком. Поэтому актуально иметь для такой терапии хорошо переносимые препараты, которые в лечебных дозах не могут оказать депрессивного действия на жизненно важные функции. Известно, что сильные наркотические анальгетики, такие как морфин, фентанил, при назначении изнуренному болью пациенту, после устранения боли, выполняющей роль активирующего фактора, могут вызвать глубокую центральную депрессию, опасную для жизни $[1,2]$. Безопасным опиоидом в этом отношении является трамадол, однако он недостаточен для устранения сильной боли $[3,4]$.

С позиций изложенного, оригинальный отечественный опиоид - просидол несомненно будет востребован в нашей клинической практике, особенно в свете наметившейся тенденции отечественной медицины на импортозамещение.

\section{Препарат просидол}

При разработке новых производных пиперидина Новокузнецкий Научно Исследовательский Химико-Фармацевтический институт в сотрудничестве с Институтом Химических наук МН АН республики Казахстан создали принципиально новую субстанцию (гидрохлорид 1(2-этоксил)-4-фенил- 4 пропионил-оксипиперидин) и назвали ее просидол [5,6].

Просидол представляет собой агонист опиоидных мю-рецепторов, по силе аналгетического действия превосходит препараты второй ступени (по классификации ВОЗ) кодеин и трамадол и уступает анальгетикам третьей ступени морфину, фентанилу и бупренорфину [7,8,9,3]. Производство просидола осуществляет ФГУП «Государственный завод медицинских препаратов». С мая 1993 г. просидол разрешен к клиническому применению в виде $1 \%$ раствора (ампулы по 1,0 мл) для инъекций и защечных таблеток по 20 мг. Просидол относится к наркотическим средствам [10,9,11].

После успешного завершения ряда экспериментальных работ на животных была доказана безопасность парентерального применения просидола для человека [1 $2,13,14,5,15,16,17,18,19,20,21]$. В клинике исследованы болеутоляющие свойства просидола при терапии хронического болевого синдрома (ХБС) в дооперационном периоде у больных с ишемическими болями в нижних конечностях [22,23]. Просидол вводили внутривенно и внутримышечно. В ходе исследований было выяснено, что при отличных анальгетических свойствах просидол также вызывает уменьшение периферического сосудистого сопротивления, увеличение объемной скорости кровотока сосудов в ишемизированной конечности с одновременным улучшением микроциркуляции в ней.

В многочисленных клинических исследованиях подтверждена высокая эффективность просидола как опиоидного анальгетика в большой и малой хирургии: для премедикации, в качестве анальгетического компонента общей анестезии, для послеоперационного обезболивания. Препарат с успехом применяли при ишемических болях в конечностях, при травмах и для купирования острого болевого синдрома при инфаркте миокарда, почечной, печеночной, кишечной колике и др.) $[24,9,25,26,6]$. Несмотря на это парентеральная форма просидола не нашла широкого применения, поскольку не имела значительных преимуществ перед инъекционным промедолом.

Одним из важнейших качеств просидола является наличие универсальной неинвазивной формы - защёчные таблетки, поэтому, созданный отечественными учеными опиоидный анальгетик просидол заслуживает специального внимания, как препарат для длительной терапии хронической боли у онкологических больных [7,812,13,14,15,16,17,3,4].

Просидол успешно применяется в практике МНИОИ им. П. А. Герцена для лечения сильного ХБС у онкологических больных.

\section{Материалы и методы исследования}

В данной работе обобщается опыт длительной терапии просидолом буккальным (Пб) у 578 пациентов с подробным анализом, выполненным у 152 пациентов в рамках диссертационного исследования. [7,8].

Большинству пациентов - 107 (70,4\%) проводилась симптоматическая терапия просидолом на фоне генерализации опухолевого процесса, остальные 45 больных $(29,6 \%)$ получали просидол в качестве адъювантного анальгетического средства в процессе проведения противоопухолевой химио- или лучевой терапии. Bсе исследованные больные до начала исследования имели ХБС продолжительностью от 14 до 730 дней, по поводу которого получали неопиоидные анальгетики, опиоиды (трамадол, просидол) или сочетанную противоболевую терапию. ХБС был обусловлен поражением органов пищеварения (25\%), молочных желез (18,7\%), мочеполовой $(16,2 \%)$, дыхательной $(12,8 \%)$ и других систем $(27,3 \%)$ и носил соматический, висцеральный или смешанный характер.

Учитывая этические факторы, а также состояние онкологических больных, мы применяли только неинвазивные диагностические методы. Оценку интенсивности боли в динамике проводили по шкале вербальных оценок (ШВО): 0-боли нет; 1 - слабая боль; 2 - умеренная боль; 3 - сильная боль; 4 балла нестерпимая боль. Реги- 
стрировали время и длительность максимального анальгетического эффекта просидола, рассчитывали разовые и суточные дозы анальгетика в динамике на этапах терапии. Оценивали состояние физической активности больных по 5-бальной шкале (1-нормальная активность, 2-несколько снижена, 3-умеренно снижена (постельный режим менее 50\% дневного времени), 4-значительно снижена (постельный режим более 50\% дневного времени), 5-полный постельный режим. Психический статус пациентов характеризовали по критериям: нормальный психический статус, умеренная депрессия, выраженная депрессия. Ночной сон оценивали как хороший (6-8 ч.), удовлетворительный (4-6 ч.), плохой (менее 4 ч.). Проводилась оценка побочных эффектов просидола по частоте (\%) и степени выраженности в баллах: 0-нет, 1-легкая, 2-умеренная, 3 балла - сильная степень выраженности.

Результаты исследования оценивались на этапах:

1. исходный, до начала лечения,

2. первые сутки терапии,

3. завершение подбора дозы анальгетика (3-4 сутки),

4. через неделю после начала лечения,

5. через 2 недели после начала лечения,

6. в конце 3-й недели лечения.

\section{Результаты.}

\section{Эффективность анальгезии.}

Исходная интенсивность боли на фоне прежней терапии у половины пациентов $(53,2 \%)$ соответствовала сильной или очень сильной (3-4 балла по ШВО), у 37,2\% умеренной (2 балла) и у 9,6\% слабой (1 балл). Средний показатель уровня боли составил $2,47 \pm 0,37$ баллов, т.е. был выше среднего.

Оценку анальгетического эффекта первой дозы препарата проводили только у тех 53 больных, которые не принимали наркотические анальгетики до включения в исследование и не получали одновременно лучевую или химиотерапию. Начальная разовая доза впервые назначенного просидола составила 20 мг у 51 больного $(96,2 \%)$ и 40 мг у 2 больных (3,8\%). Анальгетическое действие просидола буккального развивалось через $10-45(21,3 \pm 8,9)$ мин. после приема первой дозы и про- должалось от 1 до $8(6,0 \pm 1,8)$ часов. Значительная вариабельность времени наступления анальгезии может быть связана с индивидуальными особенностями всасывания препарата слизистой оболочкой рта с одной стороны, и характера ХБС с другой стороны.

У 21,8\% пациентов первая же доза просидола вызвала полное устранение боли, сопровождавшейся снижением ее интенсивности от исходного уровня более чем на 2 балла по ШВО. У 63,6\% больных интенсивность боли снизилась на 1,5-2 балла и не превысила степени слабой (хороший эффект). Удовлетворительный эффект (уменьшение сильной на 1 балл, т.е. до степени умеренной) после приема Пб был констатирован у 14,6\% больных.

В целом у этой группы пациентов произошло достоверное снижение интенсивности боли с $2,47 \pm 0,37$ до 0,5 $\pm 0,30$ балла ( $<<0,05)$, т. е. до незначительной. Случаев неэффективности препарата не отмечено. Все пациенты продолжали терапию просидолом после завершения 3-х недельного периода исследования. Начальная средняя суточная доза просидола в 1-е сутки терапии составила 82,2 $\pm 9,7$ мг и при дальнейшем титровании до достижения оптимального эффекта к концу первой недели терапии повысилась до $112,3 \pm 16$ мг, сохраняясь на аналогичном уровне на 2-й неделе лечения. К концу 3-й недели произошло повышение анальгетической дозы до 148,2+57 мг/сут мг, что может быть проявлением как нарастающей интенсивности ХБС, так и формирующейся толерантности к опиоиду (таблица 1.).

Нами был выполнен сравнительный анализ динамики доз Пб у трех групп больных, представленных в таблице.

В группе больных, получавших предшествующую терапию наркотическими анальгетиками $(\mathrm{n}=44)$, суточные дозы просидола были выше, чем у рассмотренных выше, ранее лечившихся неопиоидными анальгетиками и имевшими менее выраженный ХБС. Анализ динамики доз в этой группе показал, что начальная средняя суточная доза просидола составляла $114,5 \pm 15,8$ мг и повысилась через 2 недели терапии до 150,9 21,7 мг (см. таблицу 1). Большая часть пациентов этой группы была переведена на более мощные наркотические анальгетики в связи с нарастанием ХБС. Максимальная суточная доза проси-

Таблица 1

Динамика суточных доз Пб на этапах терапии у разных групп больных (n=152)

\begin{tabular}{|c|c|c|c|c|c|}
\hline \multirow[t]{3}{*}{ Группы больных } & \multicolumn{5}{|c|}{$\begin{array}{c}\text { Среднесуточные дозы на этапах исследования (мг) } \\
\text { и их прирост в \% к первым суткам исследования }\end{array}$} \\
\hline & \multicolumn{2}{|c|}{ сутки } & \multicolumn{3}{|c|}{ недели } \\
\hline & 1-e & $3-n$ & 1-я & 2-я & 3-я \\
\hline $\begin{array}{l}\text { Больные без противо-опухолевого } \\
\text { лечения, впервые получившие Пб ( } n=53)\end{array}$ & $82,18 \pm 9,66$ & $\begin{array}{l}96,36 \pm 18,89 \\
(+17,3)\end{array}$ & $\begin{array}{l}112,25 \pm 16,14 * \\
(+20,0)\end{array}$ & $\begin{array}{l}116,36 \pm 14,33^{*} \\
(+41,6)\end{array}$ & $\begin{array}{l}148,18 \pm 57,31^{*} \\
(80,3)\end{array}$ \\
\hline $\begin{array}{l}\text { Больные, получавшие Пб на фоне проти- } \\
\text { воопухолевого лечения ( } \mathrm{n=45)}\end{array}$ & $75,17 \pm 15,07$ & $\begin{array}{l}96,55 \pm 17,45 \\
(+28,4)\end{array}$ & $\begin{array}{l}94,40 \pm 12,45 \\
(+25,6)\end{array}$ & $\begin{array}{l}95,02 \pm 10,89 * \\
(+26,4)\end{array}$ & $\begin{array}{l}86,67 \pm 16,19 \\
(+15,3)\end{array}$ \\
\hline $\begin{array}{l}\text { Больные исходно получавшие наркотиче- } \\
\text { ские анальгетики (в том числе просидол } \\
\text { буккальный) }(n=44)\end{array}$ & $\begin{array}{l}114,48 \pm 15,77 \\
(100 \%)\end{array}$ & $\begin{array}{l}140,00 \pm 26,67 \\
(+22,3)\end{array}$ & $\begin{array}{l}144,44 \pm 17,31 \\
(+26,2)\end{array}$ & $\begin{array}{l}150,91 \pm 21,66^{*} \\
(+31,8)\end{array}$ & \\
\hline
\end{tabular}

Примечание: *- ${ }^{*}<0,05$ по отношению к исходному этапу. 
дола буккального в этой группе достигала 320 мг.

В группе больных (n=45), у которых Пб был назначен для купирования боли, вызванной противоопухолевым лечением, требовались меньшие дозы препарата, чем в двух других группах (см. таблицу), причем к 3-й неделе лечения просидолом его доза не только не возрастала, но имела тенденцию к снижению, благодаря реализации эффекта противоопухолевой терапии и снижению интенсивности ХБС (в отличие от прогрессирования ХБС в двух других группах). К этому времени просидол у этих пациентов был отменен и заменен слабым опиоидом трамадолом или неопиоидными анальгетиками, без симптомов отмены. На примере рассматриваемой группы можно говорить об отсутствии четких признаков толерантности и зависимости просидола по истечении 3 недель лечения.

На фоне проводимого противоопухолевого лечения и адекватно подобранной анальгетической терапии просидолом улучшались показатели качества жизни большинства больных всех 3-х подгрупп. Это проявлялось прекращением или уменьшением боли до незначительной на этапах терапии, улучшением продолжительности качества ночного сна, увеличением объема движений.

\section{Побочные эффекты.}

Начало терапии Пб наряду с хорошей анальгезией сопровождалось седативным эффектом (сонливостью), особенно в первые сутки терапии, но у большинства пациентов сонливость была преходящей и не превышала степени «слабой» (1 балл), уменьшаясь на этапах дальнейшей терапии. У $15 \%$ больных отмечена более выраженная сонливость (2 балла). Она стала причиной отсутствия существенного увеличения показателей общей физической активности (несмотря на хорошую аналгезию) за счет увеличения времени дневного отдыха. Вместе с тем, у пациентов, получавших просидол на фоне противоопухолевого лечения, произошло достоверное увеличение показателей физической активности в связи с отсутствием у этих пациентов существенной седации на фоне приема меньших доз Пб.

Важным показателем качества жизни инкурабельного пациента является состояние ночного сна. До начала приема просидола свой сон как хороший оценивали единичные пациенты (от 1,8\% до 13,8\% в разных группах), но уже в 1-е сутки терапии благодаря хорошей анальгезии и седации доля пациентов, имевших полноценный ночной сон, возросла до 51-59\%, а к 2-й неделе до 78-85\%.

Параллельно с этим происходило уменьшение числа больных со значительно выраженной психической депрессией (с $32 \%$ до 18\%) и с умеренной депрессией (с 50,5\% до 33,3\%) и возрастало число больных с нормализацией психического состояния (с 17,5\% до 48,5\%).

При тщательном анализе частоты проявления и выраженности побочных эффектов просидола установлено, что в целом они были выявлены у $85 \%$ больных. Степень выраженности их была слабой и умеренной в отношении сонливости, наблюдавшейся у 62,3\% больных, тошноты (27,3\%), сухости во рту $(65,5 \%)$, головокружения $(27,6 \%)$. Эти явления возникали в 1-5-е сутки от начала лечения, в дальнейшем на этапах терапии они нивелировались и не требовали отмены Пб. При этом следует отметить, что в аналогичной группе больных, получавших промедол, побочные эффекты выявлены у всех $100 \%$ пациентов, и их выраженность была больше, до максимального проявления в 3 балла, причем многие из неприятных симптомов сохранялись и на 3-ей неделе лечения. Несмотря на хорошие показатели обезболивания в группе с промедолом побочные эффекты этого препарата впервые проявились или усилились у всех больных уже с первых суток.

Эпизоды рвоты при приеме просидола были редкими и проявлялись только в самом начале терапии у 12-18\% больных разных групп и хорошо поддавались коррекции разовым назначением метоклопрамида (1030 мг). Заметного нарушения деятельности желудочнокишечного тракта не отмечено.

Ни у одного пациента, в том числе у получавших значительные дозы Пб (240-320 мг) не зарегистрировано случаев угнетения дыхания и кровообращения. Местная переносимость таблеток просидола хорошая. Случаев отмены препарата из-за плохой общей или местной переносимости в наших наблюдениях не было.

Наряду с приведенным анализом эффективности и переносимости просидола, выполненного в рамках специального научного исследования у 152 пациентов, мы располагаем втрое большим опытом рутинного применения этого хорошо себя зарекомендовавшего анальгетика, причем многие онкологические пациенты получали длительную терапию просидолом и благодаря ее эффективности и хорошей переносимости даже смогли временно вернуться к профессиональной деятельности.

В литературе описан случай обезболивания просидолом больного с прогрессирующим раком легкого в течение 245 дней [3]. К концу этого срока доза просидола буккального составила 300 мг/сут при очень хорошей переносимости, но в связи с усилением ХБС дальнейшее увеличение дозы Пб сочли нецелесообразным и дальнейшую терапию боли в течение оставшихся месяцев жизни больного проводили более мощным опиоидом бупренорфином в подъязычных таблетках. В период терапии этот пациент, художник по профессии, сохранял активность и работоспособность, написал несколько картин, одну из которых подарил институту. Просидол он носил в кармане и принимал по 3 таблетки (60 мг) каждые 5 часов, был удовлетворен лечением и своей независимостью от медицинского персонала.

Эффективность, безопасность и удобная универсальная форма просидола буккального при лечении ХБС от умеренного до сильного - главные преимущества этого анальгетика. Определенным его недостатком является относительно кратковременный эффект, который в большинстве случаев составляет 4-5 часов, причем его продолжительность широко варьирует у разных пациентов: от 2 до 8 часов. В этом отношении Пб уступает опиоидам в специальных формах продленного действия - морфину в таблетках ретард (продолжительность действия 12 часов) и трансдермальным терапевтическим системам фентанила и бупренорфина (72 часа). В то же время преимущество отечественного Пб перед этими дорогостоящими и дефицитными зарубежными 
препаратами состоит в его доступной стоимости, что в сложных экономических условиях нашей страны могло бы в значительной степени улучшить состояние лекарственной помощи больным с сильной хронической болью. Однако просидол остается мало востребованным онкологической и аптечной службами, хотя он производится в России в достаточном количестве. Продолжает превалировать рутинная инвазивная тактика обезболивания онкологических больных инъекциями наркотиков (промедол, морфин, омнопон), которые представляют дополнительную нагрузку для тяжелых больных, выполняются нерегулярно, не создают постоянной аналгезии и экономически такая тактика тоже неоправданна.

В настоящее время просидол внесен в соответствующий список лекарственных средств «льготного отпуска», и врачи онкологи имеют возможность назначить и выписать просидол по установленным для наркотиков правилам нуждающемуся в обезболивании онкологическому больному. Это один из наиболее безопасных наркотических анальгетиков, который может применяться пациентом самостоятельно в домашних условиях в дозах, рекомендованных врачом. При проведении противоболевой терапии врачам следует руководствоваться методическими указаниями, утвержденными Минздравсоцразвития РФ и Постоянным комитетом по контролю наркотиков 2005 г. [11], а также подробной инструкцией, которая сопровождает препарат.

Особые свойства просидола буккального - быстрое всасывание через слизистую полости рта с развитием мощного аналгетического действия без опасных побочных эффектов могут быть также полезными при разных видах острой боли, в частности послеоперационной и связанной с разными инвазивными вмешательствами. Просидол буккальный можно рассматривать как альтернативное инъекционным наркотикам быстродействующее неинвазивное противошоковое средство у раненых и пострадавших с острой травмой при их транспортировке, в том числе в медицине катастроф и военно- полевой хирургии.

Таким образом, просидол может иметь широкие показания не только в онкологии, но и в хирургии, травматологии, а также в разных областях неотложной медицины, сопряженных с сильной болью. Актуальным для онкологии является создание лекарственной формы просидола продленного действия.

\section{Выводы}

Оригинальный отечественный опиоид просидол имеет универсальную неинвазивную лекарственную форму в виде защечных таблеток, удобную для самостоятельного применения пациентами в любых условиях, обеспечивает хорошую анальгезию у большинства онкологических больных с хроническим болевым синдромом от умеренного до сильного.

Побочные эффекты анальгетической дозы просидола (разовая 20-40 мг, суточная 60-200 мг) не опасны, при необходимости хорошо поддаются медикаментозной коррекции и нивелируются в течение первой недели приема препарата.

Просидол в сублингвальных таблетках представляет разумную альтернативу традиционному промедолу в виде таблеток внутрь и инъекций благодаря универсальной неинвазивной лекарственной форме и лучшей переносимости терапии при аналогичном аналгетическом эффекте.

Просидол в сублингвальных таблетках обладает основными свойствами, предъявляемыми современной медициной к опиоидным для терапии хронической раковой боли: он эффективен, безопасен, лучше, чем другие наркотики переносится пациентами, удобен для самостоятельного применения тяжелобольными в амбулаторных и домашних условиях. Недостатком просидола буккального является кратковременность эффекта (в среднем 4 ч).

В заключение следует сказать, что производство просидола возобновлено на ГосЗМП, уже произведено достаточное его количество для оптовых закупок, и после утверждения структуры цены в начале 2015 года мы сможем получить этот препарат и применять его для терапии боли. 


\section{Список литературы:}

1. Обезболивание при раке и паллиативное лечение: доклад комитета экспертов ВОЗ [Доклад]. - Женева : Всемирная организация здравоохранения, 1992. - стр. 76.

2. Обезболивание при раке. - Женева : Всемирная организация здравоохранения, 1992. - стр. 76.

3. Осипова Н.А., Новиков Г.А., Прохоров Б.М. Хронический болевой синдром в онкологии [Книга]. - М : Медицина, 1998. стр. 187.

4. Осипова Н.А., Новиков Г.А., Прохоров Б.М., и др. Фармакотерапия хронического болевого синдрома у онкологических больных // Пособие для врачей. - М : МЗ РФ, 1997 г. - стр. 27.

5. Журбанов Б.А., Пралиев К.Д., Нурмухабетова Б.И., и др. Буккальные лекарственные формы аналгетика просидола [Журнал] // Хим.-фармац. журн. - 1993 г. - Т. 8. - стр. 38-40.

6. Хиленко Ж.Н., Моисеева Л.М. Просидол - новое лекарственное средство. Фармакология, клиника // Сб. науч. труд. «Патофизиология и фармакология боли». - М : [б.н.], 1993 г. - стр. 149.

7. Абузарова Г.Р. Оригинальный отечественный опиоид просидол в лечении болевых синдромов [Журнал] // Анестезиология и реаниматология. - 2001 г. - Т. 5. - стр. 74-77.

8. Абузарова Г.Р. Просидол в лечении хронического болевого синдрома у онкологических больных // Автореф. дисс. канд. мед. наук. - М : [б.н.], 2001 г.

9. Новиков Г.А. Основы паллиативной помощи онкологическим больным с хронической болью // Автореф. дисс. доктора мед. наук. - М : [б.н.], 1994 г.

10. Бабаян Э.А., Гаевский А.В., Бардин Е.В. Правовые аспекты оборота наркотических, психотропных, сильнодействующих, ядовитых веществ и прекурсоров. Нормативные документы. Методические материалы. Ответы на вопросы [Книга]. - М : Международный центр финансово-экономического развития, 2000. - стр. 440.

11. Осипова Г.Р., Абузарова Г.Р., Петрова В.В. Принципы клинического применения наркотических и ненаркотических анальгетических средств при острой и хронической боли // Методические указания МЗ и СР РФ. - М : [б.н.], 2005 г. - стр. 80

12. Брюзгин В.В. Хронический болевой синдром у онкологических больных [Книга]. - М : Сб.науч.трудов «Патофизиология и фармакология боли», 1993. - стр. 61

13. Брюзгин В.В., Стрелкова Р.М. Новый отечественный аналгетик просидол и его место в лечении хронической боли у онкологических больных [Раздел книги] // Сб.научн.трудов «Новое в онкологии». - Воронеж : [б.н.], 1997. - Т. 2. - стр. 212-215.

14. Брюзгин В.В. Новые возможности и перспективы лечения хронического болевого синдрома у онкологических больных [Журнал] // Фарматека. - 1998 г. - Т. 2. - стр. 34-35.

15. Исакова М.Е., Павлова З.В. Лечение болевого синдрома у онкологических боьных [Книга]. - М : Медицина, 1980. - стр. 128.

\section{Информация о соавторах:}

1. Алексеева Галина Сергеевна, доктор медицинских наук, заместитель генерального директора по лечебной работе ФГБУ «ФМИЦ им. П.А.Герцена» Минздрава России

2. Сарманаева Регина Рашитовна, врач центра паллиативной помощи онкологическим больным ФГБУ «Московский научно-исследовательский онкологический институт им П.А. Герцена» - филиал ФГБУ «ФМИЦ им. Герцена» Министерства Здравоохранения РФ
16. Исакова М.Е., Павлова З.В., Лактионов К.П. Просидол - новый перспективный аналгетик в онкологии [Журнал] // Впервые в медицине. - 1995 г. - Т. 1. - стр. 34.

17. Исакова М.Е., Павлова З.В., Цирихов С.М., Глазова Л.В. Новый аналгетик центрального действия просидол в онкологии [Конференция] // Тез. докл. 1-го Российского нацинального конгресса «Человек и лекарство». - 1992. - стр. 145.

18. Куриленко В.М., Михайлова Н.Н., Слепушкин В.Д., Уланова Е.В. Изучение новой лекарственной формы просидола на экспериментальной модели травматического шока [Конференция] // Тез . докл. Всероссийской научно-практической конференции «Актуальные вопросы медицины катастроф». - Новосибирск : [б.н.], 1994. - стр. 56-57.

19. Лукьянова М.С., Баева Т.Н., Иванова Р.А. Фармакокинетика и распределение просидола в тканях органов эксперементальных животных [Конференция] // Тез. докл. 2-й конференции Российской ассоции по изучению боли, 12-15 сент. 1995 г. - М : [б.н.], 1995. - стр. 203-204.

20. Моисеева Л.М., Мальцева Л.Ф., Романова Т.В. и др. Изучение специфической активности и токсичности просидола на неполовозрелых животных [Конференция] // Тез. докл. 2-й конференции Российской ассоции по изучению боли, 12-15 сент. 1995 г. - М : [б.н.], 1995. - стр. 308-309.

21. Моисеева Л.М.,Хиленко Ж.Н.,Куриленко В.М.и др. Фармакологическое изучение новой лекарственной формы просидола для буккального применения [Раздел книги] // Сб.науч.труд. «Патофизиология и фармакология боли». - М : [б.н.], 1993. - стр.142.

22. Брянская А.П. Лечение хронического болевого синдрома просилом у больных у больных с ишемическими болями в нижних конечностях // Автореф. дисс. канд. мед. наук. СПб : [б.н.], 1995 г.

23. Брянская Ф.П., Страшнов В.И.,Дубиткайтис А.Ю. Оценка болеутоляющего действия просидола при купировании хронического болевого синдрома в дооперационном периоде у больных с ишемическими болями в нижних конечностях [Конференция] // Тез. докл. 2-й конференции Российской ассоции по изучению боли, 12-15 сент. 1995 г. - М : [б.н.], 1995. - стр. 143-147.

24. Никода В.В. Применение отечественного анальгетика просидола в послеоперационном периоде [Журнал] // Анестезиология и реаниматология. - 1997 г. - Т. 5. - стр. 102-103.

25. Осипова Н.А., Новиков Г.А., Ветшева М.А., Прохоров Б.М., и др. Первый опыт применения нового отечественного наркотического аналгетика просидола в онкологии [Журнал] // Анестезиология и реаниматология. - 1994 г. - Т. 4. стр. 53-57.

26. Поляков В.С. Просидол - новый высокоэффективный аналгетик [Журнал] // Фарматека. - 1994 г. - Т. 4. - стр. 9-11.
3. Душакова Любовь Владимировна, документовед отделения диагностики и лечения ФГБУ «ФМИЦ им. П.А. Герцена» Минздарава России и по совместительству - заведующая лабораторией кафедры Урологии и оперативной нефрологии с курсом онкоурологии медицинского факультета Медицинского института РУДН. 
References:

1. Obezbolivanie pri rake i palliativnoe lechenie: doklad komiteta jekspertov VOZ [Doklad]. - Zheneva : Vsemirnaja organizacija zdravoohranenija, 1992. - str. 76.

2. Obezbolivanie pri rake. - Zheneva : Vsemirnaja organizacija zdravoohranenija, 1992. - str. 76.

3. Osipova N.A., Novikov G.A., Prohorov B.M. Hronicheskij bolevoj sindrom v onkologii [Kniga]. - M : Medicina, 1998. - str. 187.

4. Osipova N.A., Novikov G.A., Prohorov B.M., i dr. Farmakoterapija hronicheskogo bolevogo sindroma u onkologicheskih bol'nyh // Posobie dlja vrachej. - M : MZ RF, 1997 g. - str. 27.

5. Zhurbanov B.A., Praliev K.D., Nurmuhabetova B.I., i dr. Bukkal'nye lekarstvennye formy analgetika prosidola [Zhurnal] // Him.-farmac. zhurn. - 1993 g. - T. 8. - str. 38-40.

6. Hilenko Zh.N., Moiseeva L.M. Prosidol - novoe lekarstvennoe credstvo. Farmakologija, klinika // Sb. nauch. trud. «Patofiziologija i farmakologija boli». - M : [b.n.], 1993 g. - str. 149.

7. Abuzarova G.R. Original'nyj otechestvennyj opioid prosidol $v$ lechenii bolevyh sindromov [Zhurnal] // Anesteziologija i reanimatologija. - 2001 g. - T. 5. - str. 74-77.

8. Abuzarova G.R. Prosidol v lechenii hronicheskogo bolevogo sindroma u onkologicheskih bol'nyh // Avtoref. diss. kand. med. nauk. - M : [b.n.], $2001 \mathrm{~g}$.

9. Novikov G.A. Osnovy palliativnoj pomoshhi onkologicheskim bol'nym s hronicheskoj bol'ju // Avtoref. diss. doktora med. nauk. - M : [b.n.], $1994 \mathrm{~g}$.

10. Babajan Je.A., Gaevskij A.V., Bardin E.V. Pravovye aspekty oborota narkoticheskih, psihotropnyh, sil'nodejstvujushhih, jadovityh veshhestv i prekursorov. Normativnye dokumenty. Metodicheskie materialy. Otvety na voprosy [Kniga]. - $M$ : Mezhdunarodnyj centr finansovo-jekonomicheskogo razvitija, 2000. - str. 440

11. Osipova G.R., Abuzarova G.R., Petrova V.V. Principy klinicheskogo primenenija narkoticheskih i nenarkoticheskih anal'geticheskih sredstv pri ostroj i hronicheskoj boli // Metodicheskie ukazanija MZ i SR RF. - M : [b.n.], 2005 g. - str. 80.

12. Brjuzgin V.V. Hronicheskij bolevoj sindrom u onkologicheskih bol'nyh [Kniga]. - M : Sb.nauch.trudov «Patofiziologija i farmakologija boli», 1993. - str. 61.

13. Brjuzgin V.V., Strelkova R.M. Novyj otechestvennyj analgetik prosidol i ego mesto $v$ lechenii hronicheskoj boli $u$ onkologicheskih bol'nyh [Razdel knigi] // Sb.nauchn.trudov «Novoe v onkologii». - Voronezh : [b.n.], 1997. - T. 2. - str. 212215.

14. Brjuzgin V.V. Novye vozmozhnosti i perspektivy lechenija hronicheskogo bolevogo sindroma u onkologicheskih bol'nyh [Zhurnal] // Farmateka. - 1998 g. - T. 2. - str. 34-35.

15. Isakova M.E., Pavlova Z.V. Lechenie bolevogo sindroma u onkologicheskih bo'nyh [Kniga]. - M : Medicina, 1980. - str. 128.
16. Isakova M.E., Pavlova Z.V., Laktionov K.P. Prosidol - novyj perspektivnyj analgetik $\mathrm{v}$ onkologii [Zhurnal] // Vpervye $\mathrm{V}$ medicine. - 1995 g. - T. 1. - str. 34.

17. Isakova M.E., Pavlova Z.V., Cirihov S.M., Glazova L.V. Novyj analgetik central'nogo dejstvija prosidol $\mathrm{v}$ onkologii [Konferencija] // Tez. dokl. 1-go Rossijskogo nacinal'nogo kongressa "Chelovek i lekarstvo». - 1992. - str. 145.

18. Kurilenko V.M., Mihajlova N.N., Slepushkin V.D., Ulanova E.V. Izuchenie novoj lekarstvennoj formy prosidola na jeksperimental'noj modeli travmaticheskogo shoka [Konferencija] // Tez . dokl. Vserossijskoj nauchno-prakticheskoj konferencii "Aktual'nye voprosy mediciny katastrof». Novosibirsk : [b.n.], 1994. - str. 56-57.

19. Luk'janova M.S., Baeva T.N., Ivanova R.A. Farmakokinetika i raspredelenie prosidola $v$ tkanjah organov jeksperemental'nyh zhivotnyh [Konferencija] // Tez. dokl. 2-j konferencii Rossijskoj associi po izucheniju boli, 12-15 sent. 1995 g. - M : [b.n.], 1995. - str. 203-204.

20. Moiseeva L.M., Mal'ceva L.F., Romanova T.V. i dr. Izuchenie specificheskoj aktivnosti i toksichnosti prosidola na nepolovozrelyh zhivotnyh [Konferencija] // Tez. dokl. 2-j konferencii Rossijskoj associi po izucheniju boli, 12-15 sent. 1995 g. - M : [b.n.], 1995. - str. 308-309.

21. Moiseeva L.M.,Hilenko Zh.N.,Kurilenko V.M.i dr. Farmakologicheskoe izuchenie novoj lekarstvennoj formy prosidola dlja bukkal'nogo primenenija [Razdel knigi] // Sb.nauch.trud. "Patofiziologija i farmakologija boli». - M : [b.n.], 1993. - str.142.

22. Brjanskaja A.P. Lechenie hronicheskogo bolevogo sindroma prosilom u bol'nyh u bol'nyh s ishemicheskimi boljami v nizhnih konechnostjah // Avtoref. diss. kand. med. nauk. - SPb : [b.n.], $1995 \mathrm{~g}$.

23. Brjanskaja F.P., Strashnov V.I.,Dubitkajtis A.Ju. Ocenka boleutoljajushhego dejstvija prosidola pri kupirovanii hronicheskogo bolevogo sindroma $v$ dooperacionnom periode $\mathrm{u}$ bol'nyh $\mathrm{s}$ ishemicheskimi boljami $\mathrm{v}$ nizhnih konechnostjah [Konferencija] // Tez. dokl. 2-j konferencii Rossijskoj associi po izucheniju boli, 12-15 sent. 1995 g. - M : [b.n.], 1995. - str. 143147.

24. Nikoda V.V. Primenenie otechestvennogo anal'getika prosidola $\mathrm{v}$ posleoperacionnom periode [Zhurnal] // Anesteziologija i reanimatologija. - 1997 g. - T. 5. - str. 102-103.

25. Osipova N.A., Novikov G.A., Vetsheva M.A., Prohorov B.M., i dr. Pervyj opyt primenenija novogo otechestvennogo narkoticheskogo analgetika prosidola v onkologii [Zhurnal] // Anesteziologija i reanimatologija. - 1994 g. - T. 4. - str. 53-57.

26. Poljakov V.S. Prosidol - novyj vysokojeffektivnyj analgetik [Zhurnal] // Farmateka. - 1994 g. - T. 4. - str. 9-11.

Information about co-authors:

1. Alekseeva Galina Sergeevna, MD, deputy director for clinical work, of P.A. Herzen Moscow Research Oncological Institute of the P.A. Herzen Federal Medical Research Center of Ministry of Health, Russian Federation

2. Sarmanaeva Regina Rashitovna, physician of center of oncological palliative care of P.A. Herzen Moscow Research Oncological Institute of the P.A. Herzen Federal Medical Research Center of Ministry of Health, Russian Federation
3. Dushakova Lybov Vladimirovna, separation, document the diagnosis and treatment Moscow Oncology Institute of the Hertsen FMRC MH RF, Head of the Laboratory of the Department of Urology and Surgical Nephrology oncourology with the course of the Medical Faculty of the Medical Institute of People's Friendship University. 